\title{
Cross-Cultural Comparison of Tamale and Salt Lake City Experience of Unemployed Women With Physical Disabilities
}

\author{
Augustina Naami, \\ Department of Social Work, College of Social and Behavioral Sciences, \\ Sabin 243, University of Northern Iowa, Cedar Falls, IA 50614-0405 \\ Tel: 319-273-7485; E-mail: augustina.naami@uni.edu
}

Received: June 16, 2015 Accepted: July 22, 2015 Published: July 25, 2015

doi:10.5296/ijsw.v2i2.7834 URL: http://dx.doi.org/10.5296/ijsw.v2i2.7834

\begin{abstract}
Gender and disability interacts to create several challenges and vulnerabilities for women with disabilities. This paper explores and compares the daily experiences of unemployed women with physical disabilities in Tamale-Ghana and Salt Lake City, Utah in the United States.

Face-to-face in-depth interviews were conducted with 15 women with physical disabilities about their experiences with employment, unemployment and how unemployment affects their lives. Outcome suggests that the women encounter several challenges in their daily lives relating to mobility, family relationships, income, social participation and living arrangement. While some of the experiences undoubtedly differ between the two studies, some, interestingly, were similar across the two geographic regions regardless of the cultural differences.
\end{abstract}

Keywords: Women with disabilities, Tamale, Salt Lake City, Unemployment, Attitudes, Poverty 


\section{Introduction}

Gender and disability interacts to create several challenges and disadvantages for women with disabilities. Figure 1 summarizes oppression women with disabilities encounter in the society on the basis of gender and disability. Gender inequality in our societies is an age-old global tradition. The outer circle in Figure 1 represents society and its partriachal dogma, which oppresses women in general. Women's oppression is manifested in diverse ways including disaprity in employment, kinds of jobs women and men do, income they earned, positions they hold, training and promotion. Women are not only less likely to be employed, they receive lower wages than men even when they do equal work. 2013 statistics indicate that the global average gender pay gap hovered around 17\% (United Nations, 2013c). Also, various United Nations reports highlights the overrepresentation of women in the sevice sectors in both developed and developing countries compared to their male counterparts (United Nations, 2013a, 2013b, 2013c).

Women also suffer various forms of violence in their every day lives. For example, the National Coalition Against Domestic Voilence indicates that 1 in 4 women (24.3\%) aged 18 and older in the United States have been victims of severe physical violence by an intimate partner in their lifetime, while it is only 1 in 7 (13.8\%) for men (n.d). The report also indicates women are six times more likely to be killed in domestic violence homicides when there is a gun in the house.

Feminist movement started in the $17^{\text {th }}$ century to advocate for the inclusion of women in mainstream society. Although, this group has achieved many successes, it is criticised for considering women as a generic group and by so doing tend to ignore issues and needs of women with disabilities (Lather, 1991; Lonsdale, 1990; Rubin, 1997). This scenario is represented in the second circle in Figure 1 below.

Parallel to the discussion of the fminist movement, the disability movement exists to advocate for the inclusion of persons with disabilities in mainstream society as social, architectural, transportation, institutional, and information barriers continue to prevent them from having full access to available resources and opportunities to maximize their potential. However, the disability movement, just like the feminist movement, is criticized for not including issues of women with disabilities in their main agenda (Lonsdale, 1990; Rubin, 1997). The third circle of Figure 1 captures this situation.

Society, the feminist and disability movements all tend to marginalize women with disabilities. As illustrated in Figure 1, women with disabilities are embedded within the disability and the women's movements as well as in the society, none of which adequately address their needs. Different forms of oppression exist within each of the circles to perpetuate the vulnerabilities of women with disabilities. For example, women with disabilities are regarded as asexual in society and hence are considered incapable of performing the traditional roles assigned to women (Lonsdale, 1990). This belief, coupled with the stigma attached to disability, have diverse negative consequences on the lives of women with disabilities in all spheres of life. It is important to note that the interaction of gender and disability is more than just an addition to the impact of oppression on the lives of 


\section{Macrothink}

women with disabilities. Gender, disability, and other factors (e.g., culture, geographic region, religion, minority and social status) interact simultaneously to produce many and varied effects, all of which can have negative consequences for women with disabilities. To be visible and have their needs and issues addressed, women with disabilities have to overcome oppression and marginalization within the disability and women's movements as well as in the society in general. They have to challenge all of these structures that exist to create and maintain disability-and gender-based discrimination and other forms of oppression against them.

Existing literature elucidates the many forms of oppression women with disabilities encounter and their unpleasant consequences. For instance, the literature is explicit about the consistency of employment disparity between men and women with disabilities, women being less likely to be employed (Randolph \& Anderson, 2004; Smith, 2007), they are also more likely to receive lower pay (Ozawa \& Yeo, 2006) and are underrepresented in official and managerial positions, while they are overrepresented as sales, clerical, and service workers (Smith, 2007).

Even though several studies portray the inequality, oppression, and exclusion that women with disabilities face in their daily lives, little research is available on the impact of unemployment on persons with disabilities in general. In fact, almost no research is available on the impact of unemployment on women with physical disabilities. This paper explores and compares the daily experiences of unemployed women with physical disabilities in Tamale-Ghana and Salt Lake City (SLC), Utah in the United States.

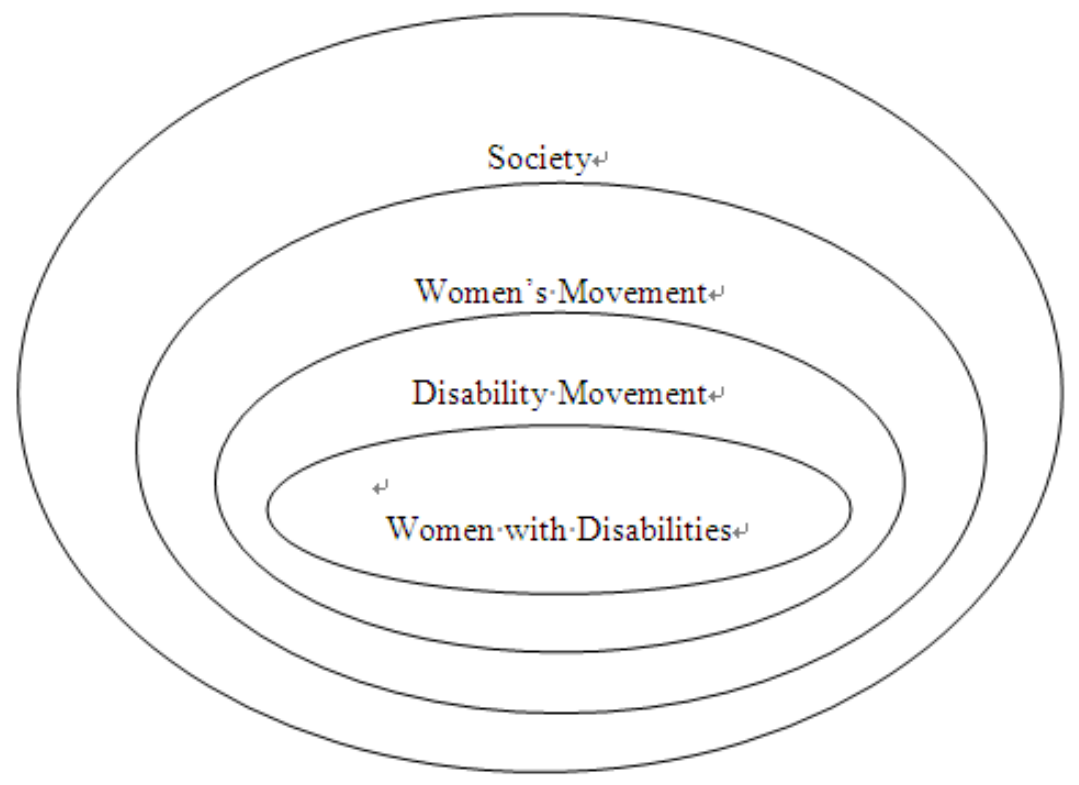

Figure 1. Diagrammatic representation of the vulnerabilities of women with disabilities 


\section{Method and Data Analysis}

The study used phenomenological qualitative research methods. Specifically, the researcher used in-depth interviews, a reflexive journal to bracket her preconceptions and experiences and a journal to record the context of the studies. These instruments were used to relevant collected to understand the day-to-day experiences of unemployed women with physical disabilities in both studies. Fifteen women with physical disabilities participated in the studies, five from SLC and 10 from Tamale. Their ages ranged between 20 and 58 years. They were all unemployed. Years of unemployment ranged between 0-25 years. Summaries of demographic information of participants are given in Tables 1 and 2.

The participants in the SLC study were recruited from the Utah Independent Living Center. Seven of the Tamale participants were recruited from the Ghana Society of the Physically Disabled (GSPD) while the other three were participated through snow ball sampling with the help of the GSPD participants. The study followed the ethical standards for human subject research provided by the Institutional Review Board of the Author's institution and was shared with participants in both study locations in the form of written informed consents which were signed before the interviews.

Participants from both study locations were interviewed, face-to-face, with an interview guide which contained several open and close-ended questions to elicit their daily experiences with employment and unemployment and how unemployment impact their lives, which is consistent with phenomenological research methodology. According to Creswell (2007), to collect relevant data for sound analysis and conclusion, phenomenological research methodologies should pose questions about participants' experiences of the phenomenon and how it affect their lives. Interviews ranged between 90-120 minutes. Only those participants who consented were audio taped. Participants in both study locations were compensated for participating in the research.

Analysis began at the first contact with respondents and remained fluid throughout the study. Daily journals recorded field observations and issues arising from the field not captured on the audio-tapes. The notes together with the recorded interviews were reviewed at the close of each interview. Issues arising from the reviews enabled the author to develop strategies to fill in gaps in subsequent interviews. The author also kept a reflective journal in which the dynamics of the research context was recorded; making her more aware about "self" to helped control biases that might be introduced into the study.

Each of the 15 audio-taped interviews was reviewed before transcription and were transcribed verbatim. The transcripts were written in the form of narratives which were read several times before the analysis. In the analysis, line-by-line coding was used. Memos and diagrams were developed to conceptualize the data to identify themes and categories. Four of the participants in the Tamale study were reconvened to review and discuss the initial themes. In SLC, findings were presented at the University of Utah Disability Studies Forum. In attendance were a variety of professionals working in the field of disability. More feedback was received from this forum. All feedback was incorporated into the analysis. The analysis for each study was done separately. The findings were then compared and contrasted to make conclusions 
about the daily experiences of unemployed women with disabilities. Pseudonyms were used in the analysis.

\section{Results and Discussion}

Six major themes emerged based on the research questions, information from the data and the literature in relation to the topic. The themes are: (1). Mobility, (2). Family relationships, (3). Income, (4). Social participation, (5). Living arrangement and (6). Unfulfilled dreams.

\subsection{Mobility}

The term mobility summaries how unemployed women with physical disabilities get around and the difficulties they encounter. This includes access to affordable mobility aids, accessible and affordable transport and availability of accessible sidewalks. While in the United States the government provide for the mobility aids of persons with physical disabilities through Medicaid and Medicare, the situation is not the same in Ghana. About $50 \%$ (5) of the women in the Tamale study used tricycles (three-wheel bicycles). However, they noted that they depended on benevolent individuals and organizations such as Catholic Priests and Nuns for the acquisition and repair of their tricycles. Ninash's narration exemplifies this situation:

"The other thing I can think of is that I am having problems with my tricycle. Sometimes when I come out and the tricycle breaks down, I don't know what to do; I don't know where to go unless people help me to repair it, because I don't have the money to pay for the repairs."

Lack of sidewalks, accessible buildings and transportation all further affect the mobility of the women in Tamale. Participants claimed that the lack of sidewalks compelled them to use the main roads which are associated with several risks, including running into reckless drivers, motor and bicycle riders, occasional accidents, and harassment from other road users. This finding is consistent with the literature indicating that barriers such as unavailable and broken sidewalks or sidewalks overgrown with weeds and no curb cuts or ramps sometimes force persons with disabilities on the main streets, regardless of their concern for their safety (Lubin, 2012; Naami \& Liese, 2012). Despite these dangers, the participants said they must provide for themselves and their children. Gina described this situation:

"The road itself has problems. When riding on them, we have a lot of difficulties. Sometimes people will be using the motor bicycles and bicycle riders will be crossing in front of you or even pushing your chair away but you can't say anything because if you do, they will insult you. One day, my friend and I were going home. Her son was sitting on her lap and then a bicycle rider ran into her tricycle. She and her baby both fell out of the tricycle. The child hit his head against the street and hurt himself. The rider didn't even help them. He rather insulted the woman and said "you disabled people when you get up you will not sit at one place. You will be going up and down town disturbing us." Someone else came to help my friend and the son. We always cry when we are out in town because when you are out there, people can insult you for nothing but you can't say anything but I can't sit in the house, who 
will take care of me? I can't get something to supplement what my husband will give me so I have to go out every day."

Lack of accessible transportation system in Ghana is another challenge identified. Despite the fact that transportation plays a vital role in everyone's life, as people need to do their daily chores, the women said they struggle to get in and out of vehicles anytime they travel, making it difficult for them to travel to places. Studies show that the lack of accessible transportation is the greatest factor affecting the employment (Aldred and Woodcock, 2008; Belgrave and Walker, 1991; Casner-Lotto \& Sheard, 2009; Lubin, 2012; Naami, 2010), education, health care, and overall social inclusion of persons with disabilities (Aldred \& Woodcock, 2008; Naami, 2010). Gina gave an example of this condition:

"Because now if I want to travel to do business, someone has to help me to get in the bus, otherwise I can't travel. Sometimes, it is even difficult to get the ticket .... Because I can't stand in the queue. I have to pay someone to help me. One day I was going to Wenchi and when I got to Techiman, there is a bus I couldn't get in. Two people had to help me get in. One held my head and the other my legs...... didn't feel good at all about that and if the government helps us this way, we will be very happy."

The SLC study presented slightly different results. In addition to the paratransit service and an accessible public transportation system, 80\% (4) of the participants had powered wheelchairs sponsored by the government (note that they paid co-payment and deductibles for those chairs). Buildings and sidewalks are also accessible. However, evidence from the SLC study suggests that drivers/passengers' attitudes and paratransit service arrangement largely affect the mobility of the participants. Three of the five women used Utah Para-transit services. However, only one of them has unconditional eligibility, i. e., Para-transit service covers pickups from her house to- and-from. The other two women had conditional eligibility; meaning the Para-transit services covers pickups from their houses to the nearest public transport system from where they continue their journey. This arrangement, they noted, is sometimes very inconvenient, especially during severe weather conditions (snow and rain weathers), and hence hinders them from doing things they want to do as Wanda notes; "For one thing I would probably go and visit my family more, I will go to different stores, I will go to see different places, and just these different things I wanted to go and see." Those who have tried using the public transportation system narrated negative experiences with both drivers and passengers.

"Hetty: We were at my friend's parents' for summer, and we were there and it was the last bus coming back home and we were at the bus stop very early. He (driver) just passed us right by, and it was the last bus of the day, and he took off. He wouldn't even stop for us. And he has to see us because it was a very well lit bus stop. So my friends parents had to get their van out, it wasn't running good, that is why they couldn't take us home, but they took us to the trax [train], we had no other choice."

"Dana: There are times me and my husband get out on the train, or the bus, especially on the bus, and if he (driver) starts putting the lift down, for one, then other people get off the bus. They (passengers) think it will take too long to get us in and they will take off and go. ... But 
I have had people do that a few times."

It is important to note that the tricycles are the key means of transportation for the women in Tamale and their younger children, given that no single transportation system in Ghana is accessible. They carried their children on their laps on these tricycles (which have no seat belts) and are compelled to use major roads regardless of the dangers posed to their safety and that of their children. Evidence from the SLC study also suggests that regardless of the availability of public transit and paratransit services, severe weather conditions, e.g., snow or rain storms, pose challenges to the use of transit services. An alternative means of transport for the women from both studies could be private transportation (e.g., having ownership of vehicles or paying for taxi services), which, unfortunately, they cannot afford due to their financial situation.

\subsection{Familial Relationships}

This theme regards relationships with spouses and children. As illustrated in Table 1, about $50 \%$ (5) of the Tamale participants were married. Twenty percent of their husbands (2) had disabilities and an additional 20\% (2) were old men, who had retired from active employment service and had other wives, mostly able-bodied women. Polygamy is widely practiced in Ghana, especially in the Northern region (study location) where Islamic religion is dominant. Though the women reported having good relationships with their husbands, they also said their husbands were unable to provide for their basic human needs due to their economic situation as narrated by Muna:

"He's fine but because we are all disabled we don't have jobs. As for love, my husband loves me but the money is not there. That's our entire problem... The money isn't there, your husband goes to work but doesn't get any money, do you fight him? No, you try to manage whatever he gives you so that people don't hear you fighting. So if I tell you the money I get is enough for me then I am not telling you the truth."

In the SLC study, only one of the participants was married. She was married to another person with a disability. They both received Supplemental Security Income (SSI) so they had some form of income, although, they claimed it was not enough to take care of their basic needs.

In regards to children, $60 \%$ of the women in the Tamale study had an average of two children, while two of their SLC counterparts had four children. Participants from both locations indicated having immersed love for their children. They however, noted they had challenges providing for their children's basic needs due to financial difficulties which sometimes results in anxiety for them. Consequently, some of the women in both studies gave out their children to kinship and foster care. Although, it was a tough decision to make, they asserted it was the best for their children. Mina (Tamale) and Mercy (SLC) commented respectively:

"They are separated. One with my mother, one with my husband's brother and the other one is with my sister... The main reason why I gave them all out is because I can't take care of them [due to poverty]. I don't have the money to do so. If they are with someone, they may get food to eat. So I will then struggle [refer to struggling for survival] for myself." 
"I put them in a foster home with a member of the LDS church. That was where they lived for a long time. They went to school from there. Now they are grown up, and I have 4 grand-kids, 2 boys and 2 girls."

It is noteworthy that kinship care approach is used in Ghana rather than foster care in child care situations such as those discussed above. It is also noteworthy that adoptions are mostly around kinship care unlike the United States and other developed countries where children are usually adopted by non-relatives. The difference between these two approaches is mostly due to Ghanaian's belief in the family system to provide for it members regardless of their demographics. Although, modernization and urbanization has weakened the extended family system by a shift toward nuclear family structures (Dako-Gyeke, 2014), this system continues to play an important role-providing socio-economic and psychological well-being for its members.

\subsection{Income}

All study participants indicated they received inadequate income as a result of their exclusion from the labor market. However, while the SLC participants received regular income from Supplemental Security Income (SSI) benefits, the same cannot be said about the Tamale participants. Some depended on their families due to the beautiful culture which entreats Ghanaians to provide for the well-being of members of their families irrespective of their demographics. However, the quantity and quality of support persons with disabilities receive is less compared to other vulnerable groups due to the stigma attached to disability in Ghana (Naami \& Liese, 2011). Thus, the majority engaged in menial and debasing activities, such as begging, as a means of survival; validating studies indicating that lack of access to the labor market and poverty cause many Ghanaians with disabilities to resort to begging for survival (Appiagyie, 2006; Kassah, 2008; Naami \& Liese, 2011).

The estimated annual income of the women in the Tamale study was less than 371 Ghana cedis, the estimated poverty line at the time of the study (Ghana Statistical Service, 2008). The women earned an average of US\$1 dollar per day. Comparing their income to the poverty threshold income, study findings suggest all the women interviewed in Tamale lived in poverty.

The Salt Lake City study presented identical results. Estimated annual incomes of participants ranged from US\$5,000-US\$10,580. Poverty thresholds for the United States in 2008 were estimated at US\$11,201 for an individual under age 65 and US\$14,840, for two people under age 65 with one child under 18 years (U.S. Census Bureau, 2009). This implies an individual or family lived in poverty if their total income is less than the appropriate threshold. Comparing their income to the poverty threshold incomes, study findings suggest all participants in the SLC study also lived in poverty.

\subsection{Living Arrangements}

The majority of the Tamale study participants lived in their family houses. The married ones, especially those married to other persons with disabilities, also lived in their spouses' family houses. Family houses in Ghana are homes own collectively by family members. They are 
mostly build by great grandfathers or other older relatives and modified by the younger ones. Multi-generation members of the family mostly live in these houses. Through this arrangement, participants noted that they did not pay rent, water, and electricity bills, as Ninash and Awo respectively stated, "I don't pay rent and my brothers pay light and water bills." "I live in my father's house with my brothers. My brothers pay all the bills in the house but they don't give me anything."

Other participants and their husbands lived in rented houses. However, they chose to live in places without basic amenities like portable water and electricity because they claimed they could not afford to pay for these facilities. Gina noted: "We live in a house my husband rented ... Even where we are staying, we do not have electricity or pipe-borne water because we cannot afford to pay for them." In Ghana, landlords normally lease their houses/apartments for a number of years and collect rent up-front to cover the length of the lease, which is usually two to three years. Although the monthly rent may not be a huge amount of money, raising two to three years rent could be a challenge to everyone.

In the SLC study, all participants lived in rented apartments supported by the government through section 8 housing subsidy. The beneficiaries pay about $30 \%-40 \%$ of the rent depending on their income. This assistance notwithstanding, the SLC participants reported that after paying their rent they do not have much left to pay their utility and other necessities as commented by Christina and Wanda respectively:

"Christina: So I pay my rent, I pay my utilities and by the time I pay all that stuff there is not really anything left over. So it's hard to go on doing much."

"Wanda: No, no, it isn't, there is no way that a person could really live on their own and really make it comfortably on social security alone. There is no way, because with this apartment, my social security wouldn't be even to make a monthly payment on this apartment."

\subsection{Social Participation}

Social participation in this study refers to the level of one's involvement in their community or society. There are various ways one could participate in their community or society. The studies examined social participation from the following perspectives: unemployment, social support groups, access to decision making and information, and conclude that all study participants do not adequately participate in their communities and societies.

One of the reasons for inadequate social participation for the women in both studies is unemployment. Study findings suggest attitudinal barriers are one of the major challenges among others, hindering the employment of women with physical disabilities in both studies.

Participants claim employers' stereotypical behavior towards them has made it difficult to get jobs.

"Dana (SLC): Even with an able bodied person, they see women, they see a shadow mirror, a weakling, you know, they see inability just because of their gender. I mean being a woman with a disability and looking for a job, it is more disadvantaged than being a man with a 
disability. Just because of the fact that they (employers) say, oh, she is a woman, oh, she is a weakling, oh, and she is in the chair, so that is going to make her twice as weak as a man."

"Mavis (Tamale): Some people think that women with disabilities are incapable of doing any good work. Its only when you are lucky and someone comes to test you and you pass the test that they may bring many more people to do business with you. When they trust you, they will come; those who don't trust you will not come because they will think you can't do the job. Similarly, when you are looking for a job, those who trust you will try you and if someone wants to say persons with disabilities can't do any good work, they will say no because they have tried you and you were ok. Those who don't trust us, they are those that when we are looking for jobs, they don't want to give them to us."

Some women in the SLC study identified employers' unwillingness to accommodate them as a cause of their exclusion from the labor market, supporting World Health Organization (2011) study indicating lack of accommodation on the job affect the employment of persons with disabilities.

"Hetty: Oh, yeah, I tried going back to work a couple of different times. ....And I have to be able negotiate to work for less hours, you know, for my son, he is my number one priority, you know, so I need to work from the time that he is out in the school, and when he is home, I have to be at home. And it's hard to find a job for those short hours. And if I could work part-time, that would be great, I would love to. I wanna work, but trying to find a job is a joke. It's frustrating in today's economy."

"Dana: Well, for one thing, it must be an easy job and it will only have to be not very long, because I wouldn't be able to work for many hours, and I wouldn't know where to go to get something easy, you know, for just a few hours. It's hard to find that kind of job."

These findings support studies indicating that attitudinal barriers are the primary obstacles to employment opportunities for persons with disabilities (Heymann, Stein \& Moreno, 2014; Mizunoya \& Mitra, 2012; World Health Organization, 2011).

Another barrier to the employment of the women in the Tamale study was inadequate education and skills training, validating studies demonstrating that inadequate skills and formal education significantly impacts the employment of persons with disabilities (Mistra et. al., 2011; Mizunoya \& Mitra, 2012; World Health Organization, 2011). It is important to note that only one of the participants in the Tamale study completed middle school education. The rest either dropped out of school or had no formal education (see Table 1). Also, the training period at the rehabilitation centers, where the women received their training, is two years while similar trades outside the centers is four years.

Educational outcomes from the SLC study were different: $40 \%$ had some college, another $40 \%$ had a college education, and $20 \%$ had a master's degree (see Table 2 ). These differences could be attributed to the existence of functional laws and regulations in the United States to protect the human rights and well-being of Americans with disabilities. Instances are the Americans with Disabilities Act and Section 504 of the Rehabilitation Act. Section 504, for example, makes specific provisions for the education of Americans with disabilities. 


\section{Macrothink}

The final barrier to the employment of the women in Tamale is exclusion from funding opportunities. The study shows that those women who desired to establish and run their own businesses could not do so because they were excluded from funding opportunities as all participants answered no when asked whether they have ever accessed/received government services/available resources/microcredit funds. This finding is consistent with the World Health Organization's World Disability Report (2011) which indicates that women with disabilities are particularly disadvantaged to start-up capital due to the lack of collateral security which is a requirement of many banks for loans.

Due to their exclusion from the labor market, some women with disabilities in both studies tried to own and run their own businesses. Study outcomes suggest that while exclusion from funding opportunities, attitude, and rehabilitation issues prevented those in Tamale from establishing their own businesses, fear of losing their Supplemental Security Income (SSI) eligibility is the major reason SLC study participants tend not to work or own businesses. Eligibility for SSI also qualifies persons with disabilities in general for other essential medical services and devices, which they cannot afford on their own. Supplemental Security Income eligibility is tied to the lack of ability to work, hence has restrictions on earnings and assets. Failure to maintain eligibility for SSI (e.g., working more than required hours or earning more than required income), results in the loss of SSI and other benefits. If a person wants to be financially independent, he/she must find a well-paying job that could pay the high medical costs associated with disability (Lonsdale, 1990) and extra costs associated with living with a disability (Ervin, 2009).

Participants indicated that employment is empowering because it is the primary source of income security and independence. They lamented how unemployment renders them powerless, dependent and prone to various societal abuses because they could not earn enough income to provide for themselves and their families. Maliya (Tamale) stated:

"For example, if I woke up in the morning, dressed up nicely and tell everyone I am going to work, they will be proud of me. Because they will think that I am not like other disabled people who stay in the house doing nothing or begging. I will go out and look for something for myself and my kids; that's very meaningful. Working is very important. If you have a job you don't have any problems with anyone. For example, if I were working and I am sick, I won't go to someone for the person to insult me saying... Employment is very important."

Participants see employment as not only a source of income but also an opportunity for social participation and psychological well-being as Mercy, SLC study notes:

"It's (employment) a lot of things. Independence, socialization, monetary aid, mental health, for me, I mean because I know with me having a job, I feel more mentally alert. I feel more confident in myself; I feel more accomplished in life, like I am actually a productive member of the society."

Despite the importance of employment as discussed above, none of the 15 participants was unemployed. The majority of participants in the Tamale study had never worked their entire lifetime while those in the SLC study had been unemployed anywhere from 3-25 years. It is 
noteworthy that unemployment affects their social support networks because they could more likely have established more support networks if they were working.

Participation in social support groups could have helped in building social relationships that might provide emotional and practical support which in turn could create access for valuable information about important resources including job opportunities reduce loneliness associated with the unemployment of women with disabilities and funding opportunities, especially for the small businesses of those in Tamale.

However, the only social support group readily available to all five participants in the SLC study was Utah Independent Living Center, although two of them said they also attended the Church of Jesus Christ of the Later-Days Saints. This finding was similar to the Tamale study. The Ghana Society of the Physically Disabled (GSPD) was the major social support readily available to all seven participants recruited from the group. Study findings therefore suggest that unemployed women with physical disabilities have limited opportunities for social participation.

Some of the reasons cited by the women for limited participation in social support groups include inability to pay membership dues and fees as well as transport costs to and from meetings.

In addition to the sources of social exclusion discussed above is lack of information. Limited social participation affect the amount of information that can help improve on their employment situation as well as their emotional and other forms of support which could reduce their loneness. Christina, SLC and Hira, Tamale studies noted respectively:

"You don't really know about them until someone tells. It's like I don't know where to look and get that stuff. I won't even know where to look. I don't know, I don't really know, because I hibernated for years. I hardly ever left my apartment until I start coming here (referring to UILC)."

"Sometimes from GSPD, at meetings they will inform us the government has given out some money for persons with disabilities. But I don't ask how to get the money. They don't tell us how to go and get the money. If they just say the money is at the district assembly, how can you just get up and go for it?"

This finding is consistent with the United Nations Development Program (2009) report which indicates that lack of information is a source of social exclusion for persons with disabilities.

The final form of social exclusion identified in these studies stems from inadequate representation in decision-making at all levels in mainstream society. The women blamed their exclusion from decision-making on their impairment, unemployment and gender. Zira and Mercy from the Tamale and SLC studies commented respectively:

"That is why I want to do something so that people will know I am also there so that they will start involving me in decision-making. If government gives me a place to sit and work and everybody knows I work here or there, maybe they will start involving me in decision-making." 
"Before, it was good until my nurse aid [female] got sick. Now I only have male nurse aids, but I want a female nurse aid. Because the male nurse aids give me shower and all that and I don't want no man to give me a shower but I have no choice about who I want to be my personal assistant."

\subsection{Feelings about Life}

Participants from both studies admitted they believed their dreams are unfulfilled because they did not have many opportunities to be productive members of society. However, regardless of the numerous challenges they encountered in their daily lives, study participants reported having good feelings about life in general. They noted life could be tough for everyone, disabled and able-bodied people alike; however, they believed that sometimes they handled difficult situations better than their able-bodied counterparts as they always face difficult life situations and have developed better coping mechanism.

"Wanda (SLC): Life is good. And you have to deal with what you have to deal with. There are some people who are angry and mad. Umm they are just mad at the world and think that the world owes them, you know, umm, but I am not that way. You've got to move on, you've got to focus on what you can do and find the way to do different things that needs to get done. You just got to move on and get it done, and get the best you can do with what you got."

"Muna, Tamale: I feel okay, what else can I do, I have to manage. In this world, there are times you won't get what you want. Other times, you get what you want. I thank God I am healthy, and if I get a long life, I know things will get better."

\subsection{Summary of Discussion}

Figure 2 graphically summarizes major study findings related to the two studies. Study findings suggests that all study participants lived in poverty. This finding is consistent with the literature indicating that persons with disabilities are more likely to be poor, especially in developing countries (Appiagye 2006; Kassah 2008; Naami \& Liese 2012, Mitra et al., 2011; World Health Organization, 2011). Poverty from this study stems from inadequate income due to unemployment, the interaction of disability and gender as shown in the left upper portion of the Figure 2. Most study findings listed under the major themes mobility, familial relationships, income and living arrangements and social participation indicated in the effects of poverty box, on the right upper side of Figure 2, are directly linked to poverty.

Inadequate social participation results from the unemployment of women with physical disabilities and their non-participation in social support groups as demonstrated in the lower portion of the diagram. Inadequate social participation has a bearing on the information unemployed women with physical disabilities receive and their inclusion in mainstream society. 


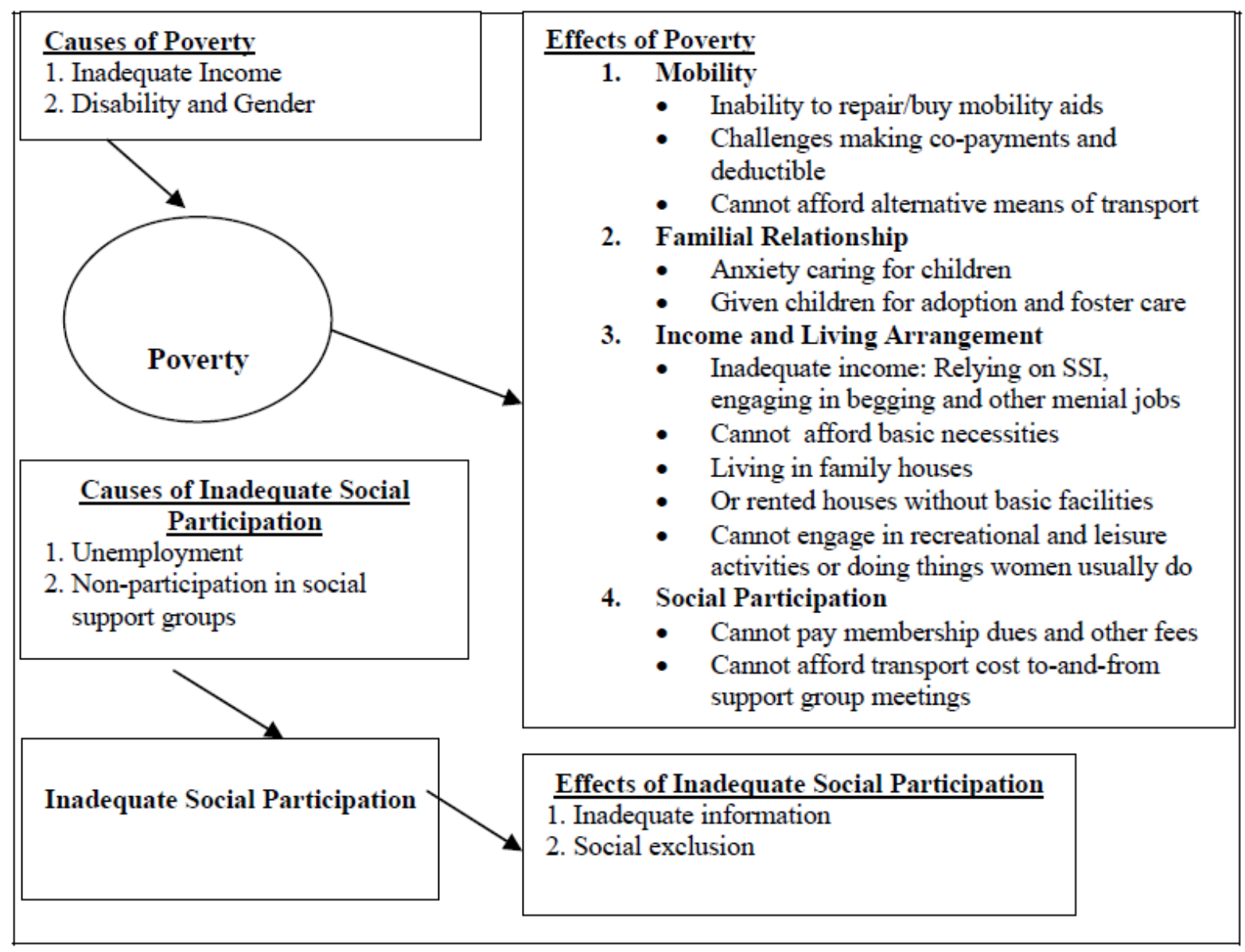

Figure 2. The relationships between study outcomes, poverty and social participation

\section{Recommendations and Conclusion}

The studies, like every other study has limitations. The results cannot be generalized to the entire population of women with physical disabilities in Tamale or Salt Lake City, Ghana or the United States as a whole due to the use of non-probability sampling methods. The sampling method used, recruiting participants from the Ghana Society for the Physically Disability and Utah Independent Living Center might have introduced selection bias to both studies. Additionally, both samples are small and may not represent the population of women with physical disabilities in these towns and countries. These limitations notwithstanding, the following recommendations could advance the employment of persons with disabilities, specially, women with physical disabilities in these countries.

\subsection{Recommendations for Ghana Government}

Given the importance of mobility aids to the women as discussed in the previous section, it is imperative for the government of Ghana to consider supporting these women to acquire mobility aids as suggested in the Persons with Disability Act 712 (PWDA, 2006). The government can instruct the District Assemblies (local governments) to finance mobility aids 
for persons with disabilities in general, especially women with physical disabilities, who cannot afford to buy them, with part of the District Assembly Common Fund (DACF). In 2007, the government of Ghana gave a directive instructing all District Assemblies to allocate $2 \%$ of their shares of the common fund for persons with disabilities (Republic of Ghana, 2009).

The government of Ghana should also offer resources for women with physical disabilities to enable them provide for their children. To do this, the government could broaden the eligibility requirement for the social protection program-Livelihood Empowerment Against Poverty program (LEAP). LEAP program seeks to alleviate short-term poverty by providing cash and health insurance to extremely poor households across Ghana (Handa, Park, Darko, Osei-Akoto, Davis, \& Diadone, 2013). Among the eligible participants is "person with extreme disability unable to work" but it is unclear how this category is defined. This support might help women with physical disabilities keep their children and live happily together instead of giving them out to kinship care.

\subsection{Recommendations for the United State Government}

Given the tight requirements for maintaining eligibility for SSI and the effect on formal and informal employment, it is critical for the United State government to re-examine SSI and its eligibility requirements. The current requirements seem to be inherently work disincentive as some of the participants noted. The government could for example allow recipients, especially women with physical disabilities to work full time for a certain number of years and still receive full benefits until they are able to sustain themselves independently.

Also, it is important to train more caseworkers to help persons with disabilities in general, including women with physical disabilities, to understand SSI and its numerous and confusing governing rules as well as the range of options available to these recipients. Solving this dilemma of work disincentive rule, could perhaps help increase the employment of women with physical disabilities as well as decrease their frustration with the program.

\subsection{Recommendations for United States and Ghana Governments}

Women with disabilities encounter multiple disadvantages on the basis of their gender and disability. Evidence from both studies suggests that attitudinal barriers are the primary source of the exclusion of the women from the labor market. Thus, it is imperative for both governments to target awareness creation about the economic and social contributions that women with physical disabilities are capable of making to national development. Awareness raising campaigns must target all sections of the society including employers, politicians, policy-makers, religious leaders, teachers, health and social service professionals, persons with disabilities and their families and all other opinion leaders.

Employers in the United States and Ghana should be educated about the ADA and PWDA tax benefits to employers for employing and providing accessible work environment for persons with disabilities.

In conclusion, disability and gender interact to create multiple vulnerabilities and unique 
challenges for women with disabilities. The two studies discussed in this paper highlight some of the challenges women with physical disabilities in Tamale, Ghana and Salt Lake City, Utah in the United States encounter in their daily lives. The challenges relate to mobility, family relationships, income, social participation and living arrangement, all of which emanate from poverty due to their unemployment, culture and societal attitudes. The women from both studies could not provide for their children and, hence, they gave out them for kinship or foster care. While the women in Tamale mostly gave their children to kinship care, their counterparts in SLC gave their children to foster care and this is due to the cultural differences in both countries. Poverty compelled the majority of study participants in Tamale to live in their family houses or in apartments without amenities such as portable water while their counterparts in SLC lived in rented apartments which were subsidized by the government. However, they also lamented that after paying their part of the rent $(30 \%-40 \%)$, they have nothing left for utilities and other necessities.

The study also concludes that all study participants do not adequately participate in their communities and societies due to unemployment, lack of access to social support groups, decision making, and information. While it is recommended for the government of Ghana to include women with disabilities among the beneficiaries for its social protection program (LEAP), the United States government is recommended to critically re-examine the SSI eligibility requirement which sometimes seem to be work disincentive. It is also suggested that both governments address public attitudes against women with physical disabilities as negative attitudes are identified as one of the major cause of their unemployment.

\section{References}

Aldred, R., \& Woodcock, J. (2008). Transport: Challenging disabling environments. Local Environment, 13(8), 485-496. http://dx.doi.org/10.1080/13549830802259847

Appiagyei, C. (2006). Report: Research into street begging by persons with disabilities in Accra and Kumasi. Accra, Ghana: Ghana Society of the Physically Disabled.

Belgrave, F. Z., \& Walker, S. (1991). Predictors of employment outcome of black persons with disabilities. Rehabilitation Psychology, 36(2), 111-119. http://dx.doi.org/10.1037/h0079076

Casner-Lotto, J., \& Sheard, W.W. (2009). The hidden workforce. Bridgeport, CT: The WorkPlace, Inc.

Creswell, J. (2007). Qualitative Inquiry and research design: choosing among five approaches (2n eds). Thousand Oaks: Sage Publications.

Dako-Gyeke, M. (2014). ). Future direction of the Social Work profession. In C. A. Sottie, M. Dako-Gyeke \& J. N. Walls (Eds.), Social work in a changing world. Social Sciences Series, 7, 185-188.

Ervin, M. (2009). Poverty and disability greatly correlated, new study shows. Chicago Tribune. $\quad$ Retrieved November 4, 2009, from http://www.chicagotribune.com/news/nationworld/sns200911040805mctnewsservbc-poverty- 
progressive-,0,3993221.story

Ghana Statistical Service. (2008). Poverty trends in Ghana in the 1990s. Retrieved August 8, 2008, from http://www.worldbank.org/html/prdph/lsms/country/gh/docs/PovProf.pdf

Handa, S., Park, M., Darko, O. R., Osei-Akoto, I., Davis, B., \& Diadone, S. (2013). Livelihood Empowerment Against Poverty Impact Evaluation. Retrieved May 9 2015, from http://www.unicef.org/ghana/gh_resources_LEAP_Quant_impact_evaluation_FINAL_CT_20 13.pdf

Heymann, J., Stein, M., \& Moreno, G., (eds.) (2013). Disability and equality at work, Oxford University Press, New York, NY.

Kassah, A. K. (2008). Disabled people and begging justifications in Accra-Ghana. Disability \& Society, 23(2), 163-170. http://dx.doi.org/10.1080/09687590701841208

Lather, P. (1991). Getting smart: Feminist research and pedagogy within the post-modern. New York, NY: Routledge.

Lonsdale, S. (1990). Women and disability. New York, NY: St. Martins Press.

Lubin, A. (2012). Persons with disabilities seeking employment and public transportation: Findings of a New Jersey Survey. Research Report for John J. Heldrich Center for Workforce Development and the Kessler Foundation, New Jersey.

Mitra, S., Posarac, A., \& Vick, B. (2011). Disability and poverty in developing countries: a snapshot from the world health survey Discussion Paper Series. Social Protection and Labor: World Bank.

Mizunoya, S., \& Mitra, S. (2012). Is there a disability gap in employment rates in developing countries? World Development, 42, 28-43. http://dx.doi.org/10.1016/j.worlddev.2012.05.037

Naami, A., \& Liese, H. (2011). The Impact of unemployment on women with physical disabilities in Tamale, Ghana. The International Journal of Diversity in Organizations, Communities and Nations, 2(11), 117-128.

National Coalition on Domestic Violence. (n.d). National Statistics. Retrieved June 5, 2015, from http://www.thehotline.org/resources/statistics/

Ozawa, M., \& Yeo, Y. (2006). Work status and work performance of people with disabilities. Journal of Disability Policy Studies, $17(3), \quad$ 180-190. http://dx.doi.org/10.1177/10442073060170030601

Rubin, E. (1997). Rehabilitation problems of women who are blind. Sexuality and Disability, 15(1), 41-45. http://dx.doi.org/10.1023/A:1024767530957

Randolph, S. D., \& Andresen, E. M. (2004). Disability, gender, and unemployment relationships in the United States from the Behavioral Risk Factor Surveillance System. Disability \& Society, 19(4), 403-413. http://dx.doi.org/10.1080/09687590410001689494

Smith, D. L. (2007). Employment status of women with disabilities from the Behavioral Risk 


\section{Macrothink}

International Journal of Social Work

ISSN $2332-7278$ 2015, Vol. 2, No. 2

Factor Surveillance Survey (1995-2002). Work, 29(2), 127-135.

US Bureau of Census. (2009). Poverty thresholds for 2008 by size of family and number of related children under 18 years. Retrieved March 20, 2009, from http://www.census.gov/hhes/www/poverty/threshld/thresh08.html

United Nations. (2013a) Statistics and indicators on women and men. Retrieved January 20, 2013, from http://unstats.un.org/unsd/demographic/products/indwm/

United Nations. (2013b). Global employment trends for women. Retrieved September 15, 2013, from http://www.ilo.org/wcmsp5/groups/public/---dgreports/--dcomm/documents/publication/wcm s_195449.pdf.

United Nations (2013c). The world's women 2010: Trends and statistics. Retrieved September

15 ,

2013,

from http://unstats.un.org/unsd/demographic/products/Worldswomen/WW_ful\%20report_color.pdf United Nations Development Programme, Croatia. (2009). Families and persons with disabilities. $\quad$ Retrieved June, 2015, from http://undp.interactive1.hr/show.jsp?newscontainer=92068\&page $=52038 \&$ singlenewsid $=724$ 96

World Health Organization. (2011). World report on disability. Retrieved June 27, 2014, from http://www.who.int/disabilities/world_report/2011/report.pdf

\section{Copyright Disclaimer}

Copyright reserved by the author(s).

This article is an open-access article distributed under the terms and conditions of the Creative Commons Attribution license (http://creativecommons.org/licenses/by/3.0/). 